\title{
The 'taming' of Julie and her avoidant attachment style
}

\author{
(c) 2017 Valérie Perret
}

This paper has been translated and is published here with permission from Actualités en analyse tranactionelle, where it first appeared in French.

\section{Summary}

In this case study, I present the application of the model developed by Richard Erskine of 'Self in Relationship' to a client who I will call Julie. I describe the open and closed domains of contact that I observed at the beginning of the work. Then I explain how I bring this client to a state of awakening of the anaesthetised domains through an implied accompaniment and full contact, whilst respecting her avoidant attachment style.

Julie arrived at my office six years ago, when she was 33 years old. She is married with sons aged one and five. She is an intensive care nurse in a regional hospital. She is a beautiful young woman who hid her emotional experience behind a charming smile. Her smooth, pretty face made it hard to know who hid behind the warm and friendly mask.

To structure my comments, I decided to use the model of the 'Self in Relationship' developed by Richard Erskine (Erskine \& Trautmann, 1997). In this, a diamond within a circle describes the affective, behavioural, cognitive and physiological dimensions of human functioning from a relational perspective. It allows us to assess whether each of these domains is open or closed to contact. The model is especially interesting when used in conjunction with Berne's structural model of ego states. This makes it possible to explore and identify the open or closed contact domains of the different ego states of the client.

Within Julie, the emotional domain was closed. Sitting in front of her, I had the impression of being faced with a doll always sporting the same smile. I perceived no life in her, she felt empty and cut off from her feelings. To each question from me about her emotions, she responded with thinking. She had no need or desire at that time for our meetings, and I have the impression that her main desire was to hide as much as possible. I formed the hypothesis that, with an abusive alcoholic father and a depressive and contemptuous mother, the environment in which she had grown up was unfavourable for free emotional expression. Her insecurity was such that she had learned to control her emotions and repress them. As a child, she had escaped to a hut at the bottom of the garden or hidden under her duvet. In her words "Hide myself so I will not be found". The adult woman that I had in front of me continued to reproduce this mechanism inside herself. She was hiding so that I could not see her. My presence, my involvement, my interest in her, as well as my
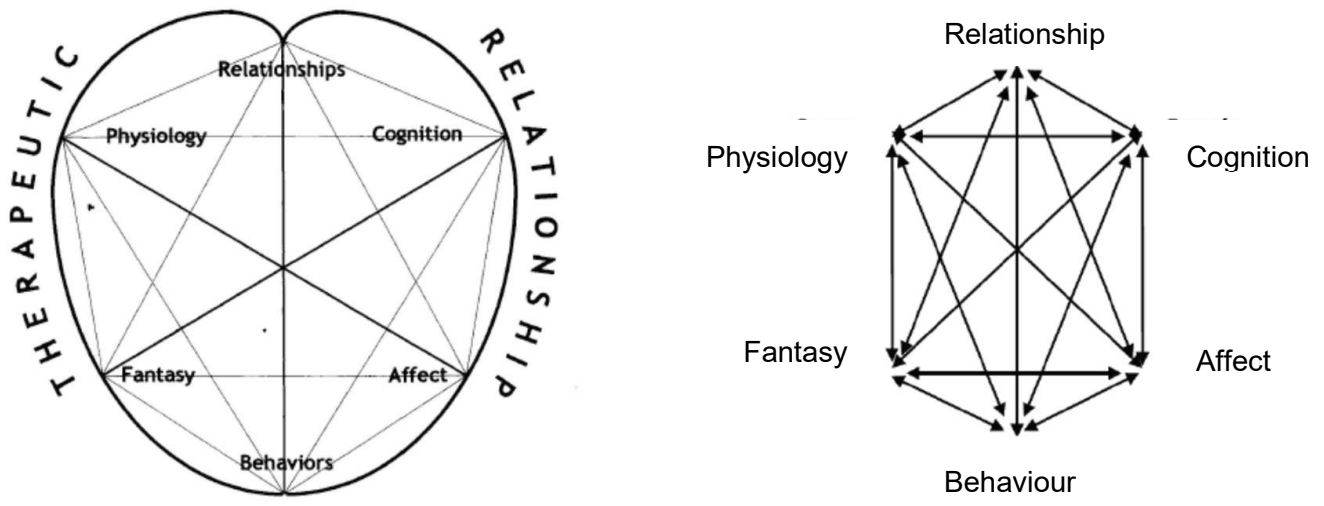
harmonisation, helped to create an atmosphere of trust within the counselling relationship. Over time, she 'thawed' and accessed her emotional memories.

Julie was particularly invested in the thinking domain, seeking to figure things out and analyse them. The little girl that she had been had tried to make sense of what was going on in her family. She had developed a belief system that brought her security, predictability and stability. Her thinking was a way of distracting herself from emotion, putting her energy into understanding in order to avoid feeling. I observed her across the sessions and was able to get her to stop and dare to make room for emotion before thinking.

Another method she used for avoiding the intimacy of the present was fantasy. For example, when she felt an intense emotion, she would begin to think of a shopping list or the organisation of the family. She dissociated. The fantasy was a hiding place where she took refuge regularly in order to automatically stabilise herself.

Julie also invested too much in the behaviour domain. She was very active. She would propose numerous activities to her children so that she could think she was being a good mother and not feel guilty. She kept a perfect house in order to have the recognition of others and to protect herself from the critical comments of her husband. She gave a lot of attention to this husband, who, according to her, needed her to take care of him. At work, she had to be devoted to her patients and make her colleagues happy. When she was doing the morning schedule, she always took breakfast for the whole team. She could not imagine not doing this as she would have felt too guilty. A deep sense of guilt was the origin of the over-investment in this domain. She had chosen her profession well, as she was an accomplished nurse who took care of everyone except herself. She pretended to be happy in a successful life. 'Doing' was protecting her deepest emotions in relation to her emotional abandonment (as a girl by her parents).

In terms of the physiological domain, her body was painful, with tension in her trapezius, jaws and back. She somaticised a lot. I formed the hypothesis that she was hiding her emotions, fear, sadness, anger, shame and resignation. Her body was telling what the emotions did not express. She had asthma and often weak respiration. We discovered later that decreased respiration was a way to be as discreet as possible and make herself invisible. This had been necessary when father came home drunk. She would be hiding under her duvet and stop breathing. In this way, she was making the least noise possible, in order not to attract the anger of her father, and she tried not to feel the fear that invaded her.
Her relationships were essentially ones of competition and over-adaptation. For example, when her husband came home from work, she would bustle around to show him she was doing lots of things, because she was afraid of his reproaches. She exhibited a lot of this over-adaptation with me. When I asked her a question, she would rush to reply and often provide three different responses for me to choose from, relieved to have been able to respond to my request. This allowed us to talk about the agitation she felt when she was required to find an answer that would be satisfactory to her questioner, and about the fear she felt about not getting things right.

\section{My support work}

For four years I waited patiently and sometimes impatiently during meetings with Julie, building the relationship. I was gently calming, at her pace, and offering her my permanent presence. I was building a secure relationship that would allow her to be more open and to access more her emotional world (as in her relational needs, as per Erskine). I proposed experimenting with being able to count on a stable, reliable and protective person (relational needs, Erskine). This was to raise awareness of what she had lacked in childhood and to allow her to restore her integrity. Julie had definitely opted for an avoidant attachment style (Erskine, 2009; Main, 1995) over 15 years of childhood.

During the four years of seeing her, I often had the impression that Julie slipped between my fingers, she escaped me, and I went through moments of helplessness and annoyance. This occurred particularly when she cancelled at the last minute because she had no one to care for her children, and had no space in her calendar to arrange another session. I did not see her during one month, which seemed to me to be long. I hypothesised that her unconscious objective in doing this was to make me powerless. Also, that she was protecting herself from attaching to me. (At this point in working with Julie, this hypothesis could not be verified directly with her. I did this later, when she had enough awareness of her avoidant style of attachment. This awareness came mainly due to the reactions of her youngest son, who 'clung' to her and showed a lot of anxiety in his relationship with her.)

I felt angry and resentful and wanted to reject her by saying "Since you don't put in more energy, figure it out yourself!". At the following meeting, she would tell me that all the sessions were very expensive! And there, in my countertransference, I was navigating between anger and guilt. I calmed down when I thought about the different psychological functions of her script: predictability, identity, continuity and stability. I remembered Julie telling me that what was 
predictable in her family were interruptions of contact, rejection and anger. Her father was often very violent, particularly when under the influence of alcohol, and her depressive mother responded to Julie's emotions with scorn and mockery. With me, she did it in such a way that the predictable (which she anticipated) would happen, in that I would become angry like her father, or reject her like her mother. This interpretation allowed me to continue to offer her my presence and my caring.

(At this point in my accompaniment, I decided not to share my thoughts about her attitudes. I judged that her Adult ego state was not yet sufficiently formed for this, and that my words could strengthen an overadaptation that was already very present. I gave meaning to my countertransference, which allowed me to be attentive to my ruptures in contact, and to maintain in that way a posture of unconditional acceptance.)

As a result, each session was an opportunity for me to show her my engagement, and my commitment to not letting go regardless of her behaviour. I also gave her the permission to define herself in the relationship with me (relational needs, Erskine). From time to time, she regularly forgot the content of our sessions, especially if they have been emotionally strong. She would forget how she had been able to be close and in contact the time before. She was very scared. She called this process "my eraser", which was the process that had been useful to forget the terror, loneliness, despair and shame that the child had felt.

As time passed, it was difficult for Julie to maintain her mask with me, and keep the loneliness and being "quiet all alone" beneath the mask. (I saw that she sought not to feel, but increasingly less effectively. Her emotions were appearing more and more quickly during sessions.) Her solitude was important for her security, and it would be dangerous to lose it. I could now give Julie a quiet and serene presence, having gained my own interior security. I had acquired awareness and also developed my skills. I felt myself to be a more powerful professional, but above all a more integrated person, with more capacity for contact with myself and others, as well as internal tranquillity. After four years to the day, she told me that she wanted to stop working with me. I hypothesised that this desire to quit could be linked to the fact that she was beginning to feel attached to me, and it scared her.

(I made this assumption based on my observations of Julie's attitudes and my knowledge of attachment. A person with avoidant attachment will do everything to avoid attachment, especially when she starts to feel it inside her. This protection system allows her to maintain predictability and continuity, and avoid feeling the pain of the juxtaposition that comes when the client feels the contrast between what is brought into the therapeutic relationship and what was not available in the past (Erskine, Moursund \& Trautmann, 1999). I saw that my alignment with her pace, my involvement, and my relational and phenomenological questioning, were destabilising for Julie. Stop, break the contact with me, allow me to maintain the stability of my system, and of my identity: "Julie, be strong, go it alone, and above all you must hide yourself, don't show your vulnerability, the others are dangerous!")

Here, I took the opportunity to prove to her that she mattered to me, i.e. I was particularly involved in taking the initiative (relational needs, Erskine) by saying to her "I think this is not the time, and I want to continue to see you." By this intervention, not only was I showing her that she mattered to me, but also that she could count on me.

She at first defended, in anger, and I calmly but firmly maintained my position. By my attitude, I convinced her. I then saw tears running down her cheeks, tears of relief that said "You see me". At the end of the meeting, she told me that if I had not insisted, she would have felt abandoned and would have said to herself "Okay, I will again stop breathing and continue completely alone." She was happy that she felt supported and protected by my position. It allowed her to feel the contact with me, of a healthy dependency and security. (The client with an avoidant attachment needs at certain times to be "held". Feeling the deep involvement of the counsellor allows her, with her repressed needs, to enter into contact. This is a very delicate moment, because the client must feel that the counsellor wants the client for herself and not for control.) 15 days later, she had forgotten the content of the meeting and smiled whilst saying that she was fine. She had replaced her mask in order to forget the proximity of our last contact.

(Speaking with her, we discovered that in forgetting, she maintained homeostasis, and thus found the security and predictability of her script and protected herself from feeling the painful emotional memories associated with the attachment figures of her childhood. Including solitude and fear. Forgetting had so many important psychological functions.)

This intervention on my part had been important in the accompaniment and had opened Julie to deeper emotional work. Through visual and physical contact, I had offered her my complete presence which she had at times accepted to feel. The full contact had allowed her to access her vulnerability. She had connected with her fear and felt her sadness, felt great loneliness and lived the despair. She was able to feel in her body the archaic decision "I cannot rely 
on you, I have to hold myself completely alone!" She knew this decision cognitively, she could feel it at a physical level, feel her need for total control, for selfcontrol, and relying only on herself.

Speaking with her, I had an image of a small wild cat that I wanted to tame. She replied "That's strange because for six years I have been trying to tame a wild cat that comes regularly to my home. I have never formed a relationship ... . it took me six years to stroke him for the first time!" I replied "And for us, it has taken only four years to meet...". She gave an amused smile, she had often complained that the work was not moving quickly enough.

During the October holidays, knowing that she might easily lose contact with herself (and with me) I took the initiative (relational needs, Erskine) of sending her a message that said "I am thinking of you.". In this way I showed her the impact she had on me (relational needs, Erskine) and that I did not forget her despite the distance. My objective was to use this message as a transitional object, and to promote the creation of a secure attachment. Not that I was not absent, but she could keep me inside her despite the separation and thus acquire the permanence of the link. When she met she told me that "That message allowed me to keep you 'a little more' with me for those three weeks." My objective was therefore achieved.

During the next meeting, she told me that she was afraid to feel, afraid to be vulnerable. Her protection system was saying to her "Be strong, guard your mask!" She was afraid to let go of her survival system, and at the same time, she felt worn down because of her daily quota of agitation and permanent over-adaptation. She felt this ambivalence very strongly inside her. Hence, I offered more frequent meetings. At first she refused, citing financial difficulties.

I explained the reasons for my proposal by saying that "I want to see you more often. I very much want you to come. I think it would be good for you. By continuing at the current rate, the permanent fear of attachment remains permanent. The more you repeat presence, the more the fear will diminish." And I took the example of the wild cat "What is it that you did that led to the taming of the cat?" . With these words, I aimed to get the seeds into her representation of a secure link that exists because of the regularity. I put in some kibble (cat treats) to have her want to come and see me more often. Her first reaction was "You will not get me!" and at the same time she felt her need to come more often. (She told me that she was more and more frustrated by the fact that our sessions were so spaced that she was forgetting the content." Inside, she felt her ambivalence: keep an avoidant attitude which allowed her to maintain predictability, continuity and stability of her script, or respond to her profound need for contact. With the consequence that she felt the pain of the juxtaposition and exposed herself to the fear of losing the link and being abandoned. To help her with her decision, I propose a body experience. I asked her to close her eyes and touch her finger to mine. I touched for an instant and then withdrew my finger.

(I meant by touch the therapeutic touch as in the example described. I use this sometimes with clients to allow them to get back in touch with their bodily sensations that have been anaesthetised alongside their emotions.)

She felt more at peace when I was present. At the moment when I removed my finger, she felt fear that I would not come back. Driven by my desire, I went back to the contact with her finger. To accept the full contact with me allowed her to reconnect with the pain of the child that she had been. She experienced a profound sadness and began to sob. Then I did the following experiment: I repeatedly touched and removed my finger, taking longer between contacts. She told me that "It's worse when you leave spaces, I have more fear." Then she added with a smile "I've got your message, I can come more often."

In the following sessions, I accompanied her in her back and forth between feeling vulnerable and taking refuge in her hiding place. I followed her, questioned her phenomenologically, helped her to put words to experiences, and sometimes I put mine. I validated her emotions, all the while being attentive to harmonising to her rhythm. My objective was for her to discover, tame and enjoy her interior self. I supported her in the meeting with her vulnerable self, as well as with her system of protection. In the place of withdrawal, it was quiet but strongly oppressive. It was however less painful than feeling the underlying emotions. Her respiration was low. I encouraged her to appreciate the hiding place, describing it as an excellent strategy for dealing with the fear she had felt as a child and which was encoded in each cell of her body.

(By hiding place, I mean the schizoid process described by Erskine as a zone of security in the presence of a threat - see article by Little on the schizoid process at www.integrativetherapy.com.)

My validation and normalisation of her system allowed her to name her hiding place in the following manner "a bubble that cradles". On sharing these words with me, she began to weep. Then she quickly returned to the bubble. After a moment of rest in that secure place, I asked her if she was willing to take 
her hand out of the hiding place and she agreed. (I had formed the hypothesis that after having obtained from me the recognition of her system of protection and having been able to sit there in my presence, she would feel safe enough with me to dare to have contact.) I put my hand onto hers. She went backand-forth between contact and rupture. She went between the intimacy with me (and feeling the pain of the juxtaposition), and thinking about something else to distract herself (the fantasy was her way to dissociate).

When she was present in the contact, she struggled between the desire to feel my presence and the decision to be alone and fend for herself "To not get caught". (This mistrust of the other was the consequence of an insecure parentage that comprised violence and humiliation." All of this she was describing to me by living it. Hence, I learned Julie's emotional language. I prompted her to bring into awareness her internal process, and to put it into words and share it. Through this work of emotional literacy in a connected intersubjective experience, I enabled Julie to define herself (relational needs, Erskine), something which she had never been able to do as a child in the environment in which she had found herself.

These sessions exemplify our work through the model of Self in Relationship. Julie was therefore in contact with her emotions, her thoughts, her physical sensations, her behaviour and her fantasies. Julie was a very different person to the woman that I had met during our first session: a Julie with domains that were open and accessible to contact. This change was possible because of my harmonisation, my involvement and my consistency within our work.

Daring to have contact with me revealed two fears to her. The fear that the contact would stop forever and she would be alone once more. She anticipated the loss and the loneliness that she already knew. (Activating the process of anticipation was a way for Julie to avoid contact and maintain the stability of her system. She protected herself from feeling profound archaic emotions.) The second fear was of being discovered, that her real self would not correspond to what I expected, and that I would reject her. In the second case, she anticipated the narrowing, the rupture and the loneliness. I thought about a third possible source of fear that would be perhaps even worse for her, in the contact taking place (That I make it and I like it). Fear of the emotions which emerge in her response to contact with me, fear of the sadness revealed by the juxtaposition. I shared this thought with her. I accompanied her in this struggle, I was simply present and allowed her to go where she wanted.
This was done with the objective of her being able to feel the full contact I was offering, without any requirement on her from me. She can live through the contrast between my attitude and the abusive attitude of her parents.

(I think that the baby in her, with the lack of secure attachment, could not integrate the permanence of the other, but did conserve emotional memories of the absence: the insecurity, the fear. I refer to the first eight stages of development of Ericsson, between birth and 24 months, which he calls the 'sense of hope'. This stage speaks of the trust or mistrust that the little person develops for others, and then for himself. When that fails, the child withdraws inside himself, because it is that which he can trust.)

\section{Conclusion}

Through this writing, I hope to pass on to you the depth and power of the Self in Relationship model as I understand it and used it with Julie. I use it differently with each client.

It is a method of intervention that can be used in different ways: it allows us to make a diagnosis, reflect on the capacity for contact of an individual, and observe which domains are open or closed to contact. It allows us to establish a treatment plan: which domains are over-stimulated and therefore over-invested in, and in which manner? Which domains, on the contrary, are needing attention and re-energisation so they can be integrated? It also allows us to observe the evolution of the client, to evaluate the work that she has already accomplished and what she still needs to do.

With Julie, we now continue our work at a faster pace; it suits her now to meet three times a month. The confidence developed within our relationship has allowed her to access a new emotion, anger: daring to feel this in daily life and utilising it to assert herself and say stop (when, for example, she does not appreciate the criticisms of her husband, when a friend behaves in a hurtful way towards her." She gradually accessed her anger through her Adult ego state in the here-and-now in her relationships. She experienced that it was not so dangerous to be assertive as she had fantasised, and that the reactions of others were not as violent as she had imagined. On the contrary, her Adult anger was increasingly well received. However she did not yet have access to the anger of her Child ego state. That was inhibited by her fear. Fear of the reaction of her internal Parent, and fear of punishment. It was down to me, during a meeting, to express my anger at each of her parents for their ill treatment of her. This intervention on my part gave her permission to become aware of her own anger and how she was 
containing it through the clenching of her trapezius, throat and jaw, without feeling able to express it.

The emotional, physiological and behavioural domains still need attention and integration. Julie is able to understand cognitively her Child anger, as well as her fantasies about the expression of such anger. However, more work is needed for a full integration of anger in all of her domains.

Following prolonged separations, such as at Christmas, she still completely forgets the content about previous sessions, especially when it comes to our relationship and the attachment between us. I find that again she is smiling, telling me that she does not know what subject to bring because all is going well for her. It is me who reminds her where we were, which I do with gentleness and benevolence. It is me who therefore maintains the permanence and constancy that she cannot yet be sure of. She is relieved that I accept this function. This allows her to avoid the effort of having to remember in front of me, the shame of not being able to do this and the fear of my reaction.

With Julie, I have learned, and am still learning, the art of creating a secure attachment with a person who has protected themselves by developing an avoidant attachment. This accompaniment has allowed me to develop a fundamental posture; stay permanently in contact in spite of ruptures, and trust the natural process of attachment of Julie, without trying to control. This was very difficult for me at the beginning of our work together. Because I was suffering from a difficulty in attachment that resembled that of Julie, and because it raised issues for me (for example during the cancelling of meetings without the possibility of rescheduling) I often felt helpless, lost, guilty of not doing a better job with her, and overcome with anxiety. I had a sensation of losing control, and I felt angry with her, with a strong wish to tell her "Figure it out for yourself because you are not putting in the energy." These emotions were invading me outside our meetings, but when I heard Julie in front of me, they disappeared and I let myself be touched deeply by this woman and by the little girl that was 'hiding' inside her.

I needed support for myself between the sessions, to deal with how I was overwhelmed by a countertransference of despair and resignation, which belonged to my story as a child as well as to
Julie. By sharing my accompaniment of Julie, I share with you also a piece of me and my personal history. Indeed, I began my training in integrative counselling shortly after the arrival of Julie in my office. During these few years, I have to do the same work that she did, to create a secure attachment inside myself. I needed to learn to take support and accompaniment in the long-term from several people (therapists and supervisors, men and women) to whom I have given my trust over time, and who have helped me tame myself. I faced my painful archaic emotions that meant I carefully avoided feeling; in particular my visceral fear of existing for the other and being seen by the other, as well as of letting the other exist for me. The unconditional support of these people, their permanence, allowed me to maintain hope when I was lost. Their confidence in me and their presence at my side enabled me to trust myself. Thanks to them, I could think about the attachment process and above all I could let it unfold within me, and be able to share it with Julie, bringing a permanent presence to all of the affective, cognitive, physiological, behavioural, spiritual and fantasy parts of her life. Thus, I have allowed her to experiment with a profound contact with herself, with me, and with others.

Valérie Perret is a Provisonal Teaching \& Supervising Transactional Analyst (Counselling) and can be contacted on pv@bizzini.ch

\section{References}

Erskine,R.G.(2009) Life Scripts and Attachment Patterns: Theoretical Integration and Therapeutic Involvement. Transactional Analysis Journal, 39:3 p207-218

Erskine, R. G., Moursund, J. P., \& Trautmann, R. L. (1999) Beyond Empathy: ATherapy of Contact-in-Relationship. Philadelphia: Brunner/Mazel.

Erskine, R.G.\& Trautmann, R.L. (1997) The Process of Integrative Psychotherapy. In. R.G. Erskine (Ed.), Theories and Methods of an Integrative Transactional Analysis. San

Francisco: TA Press [originally published as Erskine, Richard \& Trautmann, Rebecca (1996) Methods of an Integrative Psychotherapy Transactional Analysis Journal 26:4 316-328]

Main, M. (1995) Recent studies in attachment: Overview with selected implications for clinical work. In S. Goldberg, R. Muir, \& J. Kerr (Eds.), Attachment theory: Social, Developmental and Clinical Perspectives (pp. 407-474). Hillsdale, NJ: The Analytic Press. 